\title{
For Reference
}

Not to be taken from this room

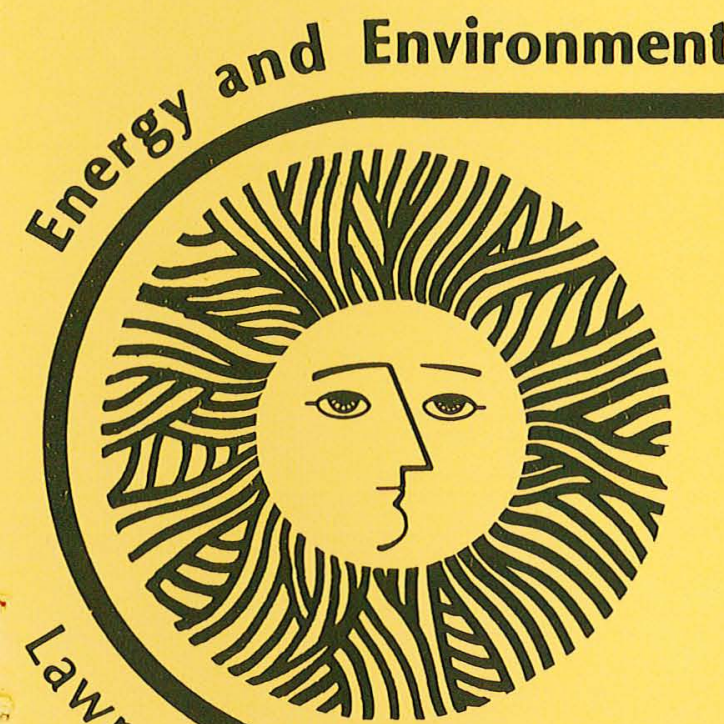

Determination Of The Recovery Stresses Developed By Shape Memory Alloys<smiles>C1CCCCC1</smiles>

H. A. Mohamed

Ce Berkeley Laboratory University of California/Berkeley Prepared for the U.S. Department of Energy under Contract No. W-7405-ENG-48 


\section{LEGAL NOTICE}

This report was prepared as an account of work sponsored by the United States Government. Neither the United States nor the Department of Energy, nor any of their employees, nor any of their contractors, subcontractors, or their employees, makes any warranty, express or implied, or assumes any legal liability or responsibility for the accuracy, completeness or usefulness of any information, apparatus, product or process disclosed, or represents that its use would not infringe privately owned rights.

Printed in the United States of America

Available from

National Technical Information Service

U. S. Department of Commerce

5285 Port Royal Road

Springfield, VA 22161

Price: Printed Copy, \$ 4.00 Domestic; \$ 8.00 Foreign

Microfiche, \$3.00 Domestic; \$4.50 Foreign 
DETERMINATION OF THE RECOVERY STRESSES

DEVELOPED BY SHAPE MEMORY

ALLOYS

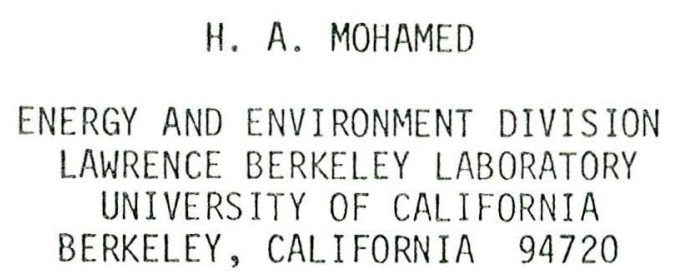

The mechanical shape memory effect is exhibited by several alloys all of which undergo thermoeleastic martensitic transformation [1]. The memory effect is demonstrated by inducing a macroscopic strain within a certain range in a specimen while in martensitic - state and then heating to revert martensite to the high temperature phase (htp). During reversion, the specimen tends to recover its original unstrained shape. Strain recovery starts at the $A_{S}$ temperature and finishes at the $A_{f}$ temperature.

One of the most interesting applications of shape memory alloys is in energy conversion devices that utilize the memory effect in converting lowgrade heat sources into useful mechanical work [2 - 4]. In evaluating the performance of a particular alloy in such devices it becomes essential to determine the levels of recovery stresses developed during the martensite htp transformation upon heating. There have been a few investigations dealing with experimental measurements of the recovery stresses developed by $\mathrm{Ni}$ - $\mathrm{Ti}$ alloys near the equi-atomic composition [5, 6]. However, no attempt has been made as yet to predict these stresses. In the present paper, a simple relation-

\footnotetext{
${ }^{*} A_{S}=$ temperature at which the martensite $\rightarrow$ htp transformation starts during heating.

$A_{f}=$ tenperature at which this transformation finishes during heating.

** A recovery stress is defined as the external stress required to balance the internal stresses that tend to revert martensite to the htp.
} 
ship has been developed between the recovery stresses, temperature and strain

For the discussions which follow, it is instructive to identify a reference point from which the macroscopic strain is measured i.e.; a zero - point strain. This can conveniently be taken to be the point at which the material consists entirely of the htp.

Consider a polycrystalline shape memory alloy that has been almost entirely transformed to martensite by cooling it to a temperature at or below its respective martensite - finish temperature $M_{f}$. In the absence of an external and appreciable internal stresses, all the martensite variants that are crystal lographically equivalent would form with equal probability. Therefore, no net macroscopic strain as measured from the zero - point would be expected and hence no recovery stresses would develop during the reverse transformation to the htp. In order to realize a recovery stress, the material must acquire a macroscopic strain relative to the zero - point. In terms of the microstructural features, this corresponds to a certain degree of directionality in the distribution of the martensite variants through-out the microstructure. It has been shown experimentally that any strain within the recoverable range is accommodated by reorientation of a volume fraction of the thermally induced martensite [7 - 10]. This occurs by preferential growth of the most favorably oriented martensite variants. It is then expected that the recovery stress, $\sigma_{r}$, would be proportional to the volume fraction of re-oriented martensite $\left(V_{M}\right)$. This determines the functional dependence of $\sigma_{r}$ on strain $\varepsilon$.

Upon heating to within the $A_{S}-A_{f}$ temperature range, a certain volume fraction of martensite tends to revert to the htp. The driving force for such reversion arises from the chemical free energy difference between the two respective structures, the elastic strain energy stored in the lattice during the transformation to martensite and energy associated with reversible defects, e.g., twins. As the temperature increases within the range $A_{s}-A_{f}$, the driving force increases and in turn the volume fraction of martensite that tends to revert to the htp ( $\left.V_{h t p}\right)$. 
It follows that $\sigma_{r}$ increases as $V_{\text {htp }}$ increases with temperature. This determines the functional dependence of $\sigma_{r}$ on temperature within the range $A_{S}-A_{f}$.

It can be concluded from the above discussion that:

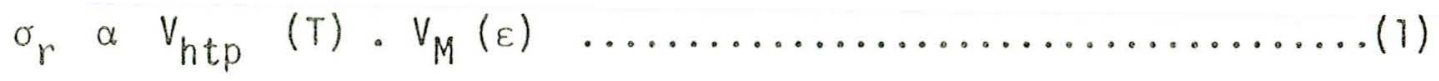

$\sigma_{r}$ would be limited by the minimum stress required to initiate irreversible plastic deformation in the martensite structure and/or the htp. The yield stresses of the htp are, however, expected to be lower than those of the martensite due to: ( $i)$ the lower symmetry of the martensite structure and ( $i i)$ the finer grain size of the martensite phase. Therefore, the proportionality constant in equation (1) can be taken to be the yield stress of the htp, $\sigma_{Y}^{h t p}$, that is consistent with the state of temperature and strain and hence,

$$
\sigma_{r}=\sigma_{Y}^{h t p} \cdot V_{h t p}(T) \cdot V_{M}(\varepsilon)
$$

From dilatometric measurements on a Ti -50.4 at pct. Ni alloy it appeared that $V_{\text {htp }}$ increases exponentially with temperature within the range $A_{S}-A_{f} \cdot V_{h t p}(T)$ could be expressed as:

$$
V_{\text {htp }}(T)=1-\exp ^{-K} \frac{\left(T-A_{S}\right)}{A_{f}-T}
$$

where $K$ is a constant which by analogy to chemical reactions, can be considered as a reaction rate constant. It is to be noted that the type of equation (3) has been found empirically to describe the kinetics of a wide variety of reactions in metals (11).

The probability that re-orientation of an existing martensite occurs under an external stress is expected to be proportional to the number $N$ of martensite variants that are cyrstallographically equivalent. If as has been assumed all the variants exist with equal probability, the interfaces contained in the microstructure (twin - boundaries in the case of $\mathrm{Ni}$ - $\mathrm{Ti}$ [7] assume all the possible orientations with respect to the applied stress. Therefore some martensite 
variants would be unaffected and others would be affected to different extents depending on their relative orientation. It then follows that $V_{M}$ would never achieve unity for any finite strain. A relation which gives $V_{M}$ as a function of $\varepsilon$ must then satisfy the following conditions:

$$
\begin{aligned}
& V_{M}=0 \text { for } \varepsilon=0 \text {, and } \\
& V_{M} \text { increases with } \varepsilon \text { (as measured from the zero - point) } \\
& \text { but never achieves unity. }
\end{aligned}
$$

These conditions can be satisfied by an exponential function of the form:

$$
V_{M}=1-\exp ^{-C \varepsilon}
$$

where $\mathrm{C}$ is a constant that can be taken to be the number $\mathrm{N}$ of crystallographically equivalent martensite variants.

$\sigma_{r}(T, \varepsilon)$ can then be expressed as:

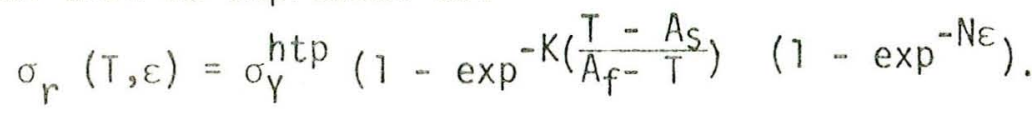

The characteristic features of the recovery stress as depicted from equation (5) are:

(i) For a given strain $\varepsilon, \sigma_{r}$ is sensitive to temperature only within the range $A_{S}-A_{f}$.

(ii) $\sigma_{r}$ achieves its maximum value of:

$$
\sigma_{r} \max =\sigma_{Y}^{h t p}\left(1-\exp ^{-N \varepsilon)}\right.
$$

at the $A_{f}$ temperature where $V_{\text {htp }}=1$.

(iii) For temperatures higher than the $A_{f}, o_{r}$ becomes sensitive only to strain.

These features are in agreement with the experimental observations [5, 6]. Experimental work is now in progress in order to compre the measured and predicted values of the recovery stresses developed by a $\mathrm{Ni}$ - $\mathrm{Ti}$ alloy. 
This work was supported by the Conservation and Solar Applications Division of the U.S. Department of Energy through the Energy and Environment Division of the Lawrence Berkeley Laboratory, University of California, Berkeley. 


\section{REFERENCES}

1) J. Perkins, ed., "Shape Memory Effects in Alloys," (Plenum Press, New York, 1975).

2) R. Banks, Naturwissenschaften, 62 (1975) 305.

3) R. Banks, in "Shape Memory Effects in Alloys," (Plenum Press, New York, 1975) p. 537.

4) R. Banks and M. Wahlig, Presented at the International Solar Energy Society Meeting, Winnipeg, Canada, Aug. 1976, Lawrence Berkeley Laboratory Report No. 5293.

5) G. R. Edwards, J. Perkins and J. M. Johnson, Scripta Met. 11 (1975) 1167.

6) W. B. Cross, A. H. Karigits and F. J. Stimler, "Nitinol Characterization Study," NASA Contractor Report (1969) Cr - 1433.

7) H. A. Mohamed and J. Washburn, J. Mater. Scien. 12 (1977) 469.

8) H. A. Mohamed and J. Washburn, Met. Trans. 7A (1976) 1042.

9) C. M. Wayman, in "Shape Memory Effects in Alloys" (Plenum Press, New York, 1975) p. T.

10) L. Delaey, R. V. Krishnan, H. Tas and H. Warlimont, J. Mater. Scien. 9 (1974) 1521.

11) J. Burke, "The Kinetics of Phase Transformations in Metals" (Pergamon Press, 1965) p. 45. 
This report was done with support from the United States Energy Research and Development Administration. Any conclusions or opinions expressed in this report represent solely those of the author(s) and not necessarily those of The Regents of the University of California, the Lawrence Berkeley Laboratory or the United States Energy Research and Development Administration. 